\title{
Microscopic experimental investigation on shear failure of solder joints
}

\author{
K.J. $\mathrm{LAU}^{1, *}$, C.Y. TANG ${ }^{2}$, P.C. TSE ${ }^{1}$, C.L. CHOW ${ }^{3}$, S.P. $\mathrm{NG}^{1}$, C.P. TSUI ${ }^{2}$ and \\ B. $\mathrm{RAO}^{1}$ \\ ${ }^{1}$ Department of Mechanical Engineering, The Hong Kong Polytechnic University, Hunghom, \\ Hong Kong \\ ${ }^{2}$ Department of Industrial and Systems Engineering, The Hong Kong Polytechnic University, Hunghom, \\ Hong Kong \\ ${ }^{3}$ Department of Mechanical Engineering, University of Michigan, Dearborn, MI 48128-1491, USA \\ *Author for correspondence: (E-mail. kcchankjlau@netvigator.com)
}

Received 14 May 2003; accepted in revised form 19 August 2004

\begin{abstract}
A microscopic investigation has been made on the shearing of one leaded and two leadfree solders by using an in situ SEM method. A shear lap joint specimen is designed and fabricated to accommodate a thin layer of solder alloy between copper strips. A non-contact method that measures strains in a very narrow area in the solder was applied. A laser grid was also used on the copper strip for measuring the back-face strain. Simultaneously micrographs at various stages were also taken. Where in situ measurements and micrographs are recorded they can reveal the continual development of damage and fracture mechanisms consistent with observations generated by low-cycle fatigue loading. This means that the shear test can be used as an alternative test to fatigue loading tests. By comparison, two lead-free solder specimens showed much smaller elongation to failure than the leaded solder, although all specimens showed similar sequence of events leading to final failure, including the boundary layer fracture phenomenon. The back-face strain indicator for the formation of a macro crack is due to the shifting of high stress concentration area from the joint-edge region to outside the joint region as revealed by a damage-coupled finite element procedure. The procedure also provides an estimate on the critical back-face strain.
\end{abstract}

Key words: Back-face strain, in situ measurements, microstructures under shear, solder joint.

\section{Introduction}

Numerous studies on properties of solder can be found in the literature, including variations in composition, temperature and loading conditions. Typically Solomon (1986) generated plastic strain versus fatigue life data for $60 / 40$ solder $(60.18 \mathrm{wt} \%$ $\mathrm{Sn}, 39.53 \mathrm{wt} \% \mathrm{~Pb}$ with $66 \mathrm{ppm} \mathrm{Zn}$ and $12 \mathrm{ppm} \mathrm{Cu}$ ) from tests run at $-50,35,125$ and $150^{\circ} \mathrm{C}$. It was found that these data could be correlated by the Coffin-Manson fatigue law, although the value of the exponent is reduced at $150{ }^{\circ} \mathrm{C}$. A model was presented which described the influence of plastic strain and cycling frequency. At $150^{\circ} \mathrm{C}$ and at low frequencies it was found that the time to failure was constant and independent of the plastic strain range, while cycling at more than one temperature caused relatively little reduction in life compared to that observed in tests where the cycling was at a single temperature. Logsdon et al. (1990) obtained the isothermal 


\section{K.J. Lau et al.}

mechanical and fracture mechanics material properties of $63 \mathrm{Sn}-37 \mathrm{~Pb}$ solder determined at $-55,24$ and $125^{\circ} \mathrm{C}$. Tensile creep-rupture, fracture toughness, fatigue crack growth rate and creep tests were performed. Using scanning electron microscopy and Auger spectroscopy, ductile transgranular fracture was observed at $-55^{\circ} \mathrm{C}$ while ductile intergranular fracture was observed at room temperature. The growth rate of fatigue cracks in $63 \mathrm{Sn}$ solder decreased with a decrease in temperature over the temperature range of 24 to $-55^{\circ} \mathrm{C}$ and, at room temperature, was found to be sensitive to a frequency range of $2-10 \mathrm{~Hz}$. Information on works of some other authors can be found in Kanchanomai et al. (2002a), in which low cycle fatigue tests of as-casted $\mathrm{Sn}-\mathrm{Pb}$ eutectic solder were carried out using a non-contact strain-controlled system at $20^{\circ} \mathrm{C}$.

Corresponding studies have also been carried out for lead-free solders. Kariya and Otsuka (1998a, 1998b) studied the fatigue life of $\mathrm{Sn}-3.5 \mathrm{Ag}-\mathrm{Bi}$ alloy, which was found to be dominated by the fracture ductility of the alloy and to obey a modified CoffinManson's law. Copper, zinc and indium were then selected as the third element. It was found their addition up to $2 \%$ slightly decreases the fatigue life of $\mathrm{Sn}-3.5 \mathrm{Ag}$ alloy due to the loss of ductility, while the modified Coffin-Mansion's equation can also be applied to ternary $\mathrm{Sn}-3.5 \mathrm{Ag}-\mathrm{X}$. Also the fatigue life of the ternary alloy is dominated not by the kinds and amounts of third element but by the ductility of each alloy. Zhao et al. (2001) carried out fatigue crack growth tests of $96.5 \mathrm{Sn}-3.5 \mathrm{Ag}$ solder at frequencies from 0.1 to $10 \mathrm{~Hz}$ and at stress ratios from 0.1 to 0.7 . Fatigue cracks were found to propagate in a transgranular manner for the specimens tested under low stress ratios and high frequencies where the fatigue crack growth behavior was dominantly cyclic dependent. Intergranular crack growth was observed for the specimens tested at high stress ratios and low frequencies, where the fatigue crack growth behavior was dominantly time-dependent.

Although information for solder behavior in the bulk form is abundant, the direct use of such information for solder joint analysis is usually inappropriate due to a number of reasons. One major reason is the presence of an interfacial boundary in a joint, which is not found in a test specimen made of bulk solder, can have a major influence on the solder failure mechanism. If a solder joint is subjected to higher temperature for extended periods of time, the intermetallic layer at the interfacial boundary grows in thickness and decreases in fracture toughness so that fracture may occur at the intermetallic layer. On the other hand, as miniaturization of electronic components progress, the solder joints can become extremely thin such that the intermetallic region has to make major contributions to the deformations. Furthermore, in the case of hard solders, low-cycle thermomechanical fatigue mechanisms may not be realizable due to the smallness in deformation, and the joint may fail at the interface instead. Another factor is that the thickness of a solder joint is much smaller than that of a specimen used for testing bulk solder so that the amount of plastic deformation can be vastly different in the two cases. Hence life prediction procedure for solder joints must be 'joint oriented' rather than just 'material oriented' for the determination of phenomenological material failure parameters.

On the microscopic scale, Clough et al. (1995) conducted shear tests on single-lap solder layers between copper plates and studied their fracture mechanisms through observations from optical micrographs. It was observed that failure of solder joints often occur along a path not immediately at the copper interface, but 
$\sim 10-20 \mu \mathrm{m}$ away from it. Possible associated phenomena include strain gradient, shear lip-opening and crack sliding friction while solder is more brittle in a joint than in bulk form. As in many studies of the same nature, the microstructures were captured well after failure so that crack initiation and intermediate crack propagation phenomena cannot be revealed (e.g. Guo and Conrad, 1996; Shang and Yao, 1996; Yao et al., 1996; Pang et al., 2001; Kanchanomai et al., 2002b). On the macroscopic scale, Zang et al. (1996) introduced a back-face strain technique for signaling crack initiation in solder lap joints.

In order to study the failure mechanism taking place at various stages of loading, a continual in situ observation (Tang et al., 2002) of the microstructure of the solder alloy is made in the present study. A lap shear joint specimen is designed and fabricated to accommodate a thin layer of solder alloy under shear loading. SEM micrographs are captured and the load-displacement data are also acquired during the shear test. Corresponding back-face strains are also measured, with a view to compare microscopic observations and finite element analysis results with the backface strain measurements.

\section{Specimen design and fabrication procedure}

\subsection{SPECIMEN DESIGN}

The major dimensions of the specimen parts are shown in Figure 1, in which the two copper beams are first shown separately and then also in the assembled configuration. The specimen comprises two copper beams soldered together to form a single lap joint. Copper was chosen in order to simulate real solder joints in practice. Three solder materials were used for testing: $64 \mathrm{Sn}-36 \mathrm{~Pb}, 97 \mathrm{Sn}-3 \mathrm{Cu}$ and $95.5 \mathrm{Sn}-3.5 \mathrm{Ag}-1 \mathrm{Cu}$. The $0.5 \mathrm{~mm}$ flange dimension on one arm and $0.3 \mathrm{~mm}$ slot dimension in the other represent two thin guides for facilitating solder containment. These guides were to be removed by lapping to expose the solder before testing is conducted so that, in the end, each copper beam would have a length of $15.1 \mathrm{~mm}$ and a depth of $5 \mathrm{~mm}$. In the soldering region, the beam thickness is $0.9 \mathrm{~mm}$. The solder region is $6 \mathrm{~mm}$ wide, $5 \mathrm{~mm}$ deep and $0.2 \mathrm{~mm}$ thick. The additional $1 \mathrm{~mm}$ slot-length on the right beam provides for the fillet area.

In order to fix the specimens onto the tension stage (Figure 2), A pair of steel fixtures were designed to mount the specimen so that the microstructure change of the solder on the side surface of the specimen can be observed. The joints were designed according to the tension stage. The dimensions and shape of the fixtures are made compatible with the tension stage (Figure 3). All the specimens and fixtures used in the tests were fabricated by milling.

\subsection{SOLDER JOINT PREPARATION}

Before soldering, the following surface preparation processes were carried out: (1) specimens with final surface finishes were obtained with fine grit abrasive and then washed with lye; (2) greasy dirt on the specimens was removed first by washing with $10 \% \mathrm{NaOH}$ solution and then with distilled water before drying; (3) to remove copper oxide, the surfaces of the specimens were first washed with acid solution 

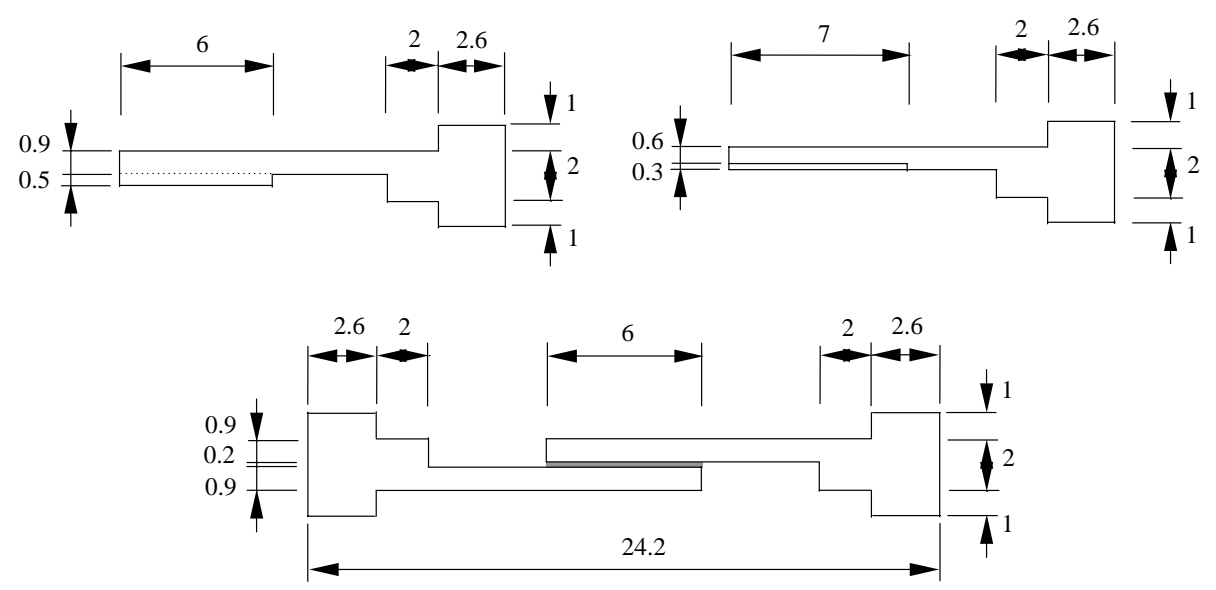

Figure 1. Dimensions and shape of the specimen.

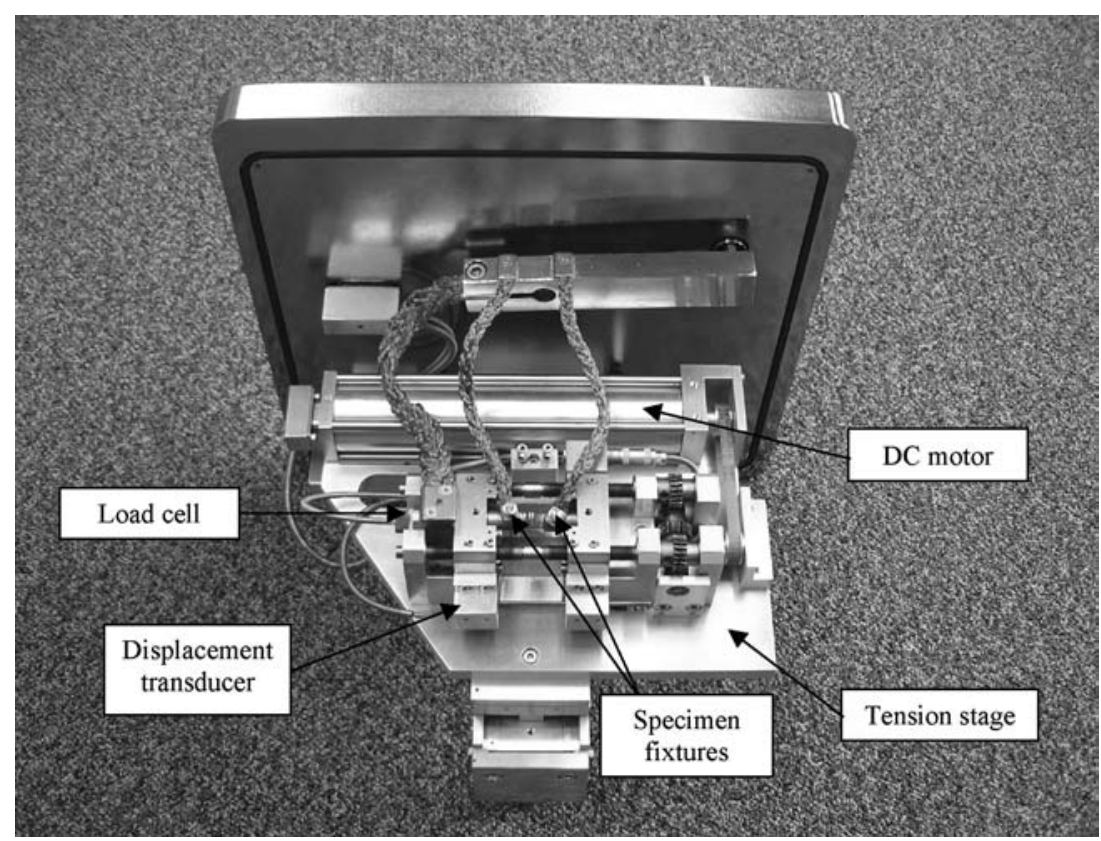

Figure 2. Tension stage.

of $75 \mathrm{~cm}^{3} / \mathrm{L} \mathrm{HNO}_{3}+100 \mathrm{~cm}^{3} / \mathrm{L} \mathrm{H}_{2} \mathrm{SO}_{4}+1 \mathrm{~cm}^{3} / \mathrm{L} \mathrm{HCl}$ and then by distilled water; (4) specimens were immersed in $10 \% \mathrm{NaOH}$ solution to neutralize the acid solution that remained on the surface of the specimens and then washed by distilled water and dried. The specimens were then kept in an airtight container.

The solder application procedure consisted of the following steps: (1) areas neighboring the soldering region were painted with a solder resist, (2) solder was applied on the area of each beam requiring soldering, the thickness of solder layer being more than $0.2 \mathrm{~mm}$; (3) the temperature control of an electric heating was set to a target temperature of $200^{\circ} \mathrm{C}$ and both beams were placed on the metal plate of the heater; (4) when the actual temperature reached $180^{\circ} \mathrm{C}$, the two parts were pressed 


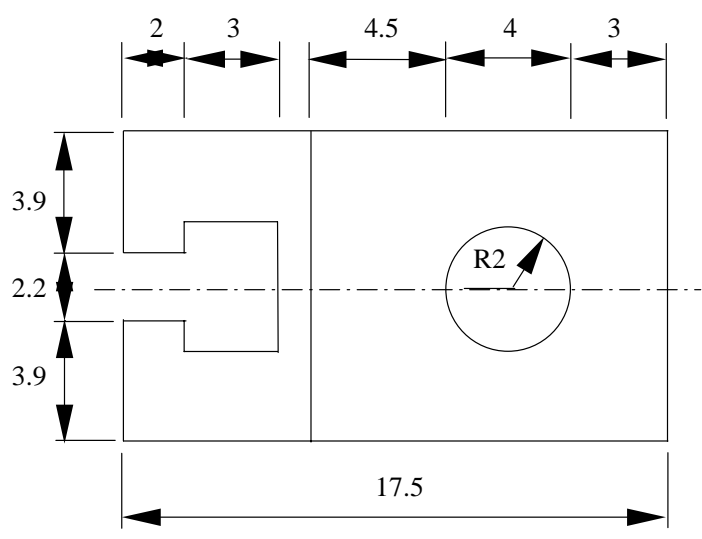

Figure 3. Fixtures.

together until the solder completely melted. Excessive solder was squeezed out and stayed on the surface of the solder resist; (5) the heater was turned off while the two parts were kept pressed together with tweezers until the temperature had fallen to $120^{\circ} \mathrm{C}$.

The excessive solder left on the solder resist was removed with ease by means of a cutter. The specimens were then polished using sequentially finer grades of abrasive paper. The guides for containing the solder were being removed by the same process. Further polishing was conducted using sequentially finer grades of diamond compounds $(6 \mu \mathrm{m}, 1 \mu \mathrm{m}, 1 / 4 \mu \mathrm{m}$ and $1 / 10 \mu \mathrm{m})$, until all scratches on the surface of the solder were removed. $100 \mu \mathrm{m} \times 100 \mu \mathrm{m}$ micro-grids were laser-marked on the specimen for back-face strain measurement by using a $90 \mathrm{~W} \mathrm{Nd}$ : YAG laser marker. At an operating current of $13 \mathrm{~A}$ and pulse frequency of $1000 \mathrm{~Hz}$, the grids were marked at a speed of $10 \mathrm{~mm} / \mathrm{s}$ with two repetitions of marking cycles.

\section{Testing and data acquisition}

\subsection{LEADED SOLDER $(64 \mathrm{Sn}-36 \mathrm{~Pb})$}

The initial microstructure of the solder is shown in Figure 4. Each specimen was held firmly by a loading fixture and the whole setup was placed inside an enclosed chamber in order to facilitate the SEM observation. All the tests were performed at room temperature. Leica SEM, model STEREOSCAN 440, was used in the tests. The applied force and the extension of the specimen were recorded by one computer, while the corresponding microscopic graph was captured by another computer. Tensile loading was applied to both ends of the fixture so that the solder material in the specimen was under shear loading. The applied force was measured by a load cell with a maximum capacity of $5 \mathrm{kN}$ while the displacement was measured by a displacement transducer on the tension stage. The cross-head speed of test was set to $0.5 \mu \mathrm{m} / \mathrm{s}$.

Shearing force was applied to the solder joint by the specially designed tension stage. During the test, force and cross-head displacement data as well as in situ SEM micrographs were captured using a data acquisition system. With the aid of the image 

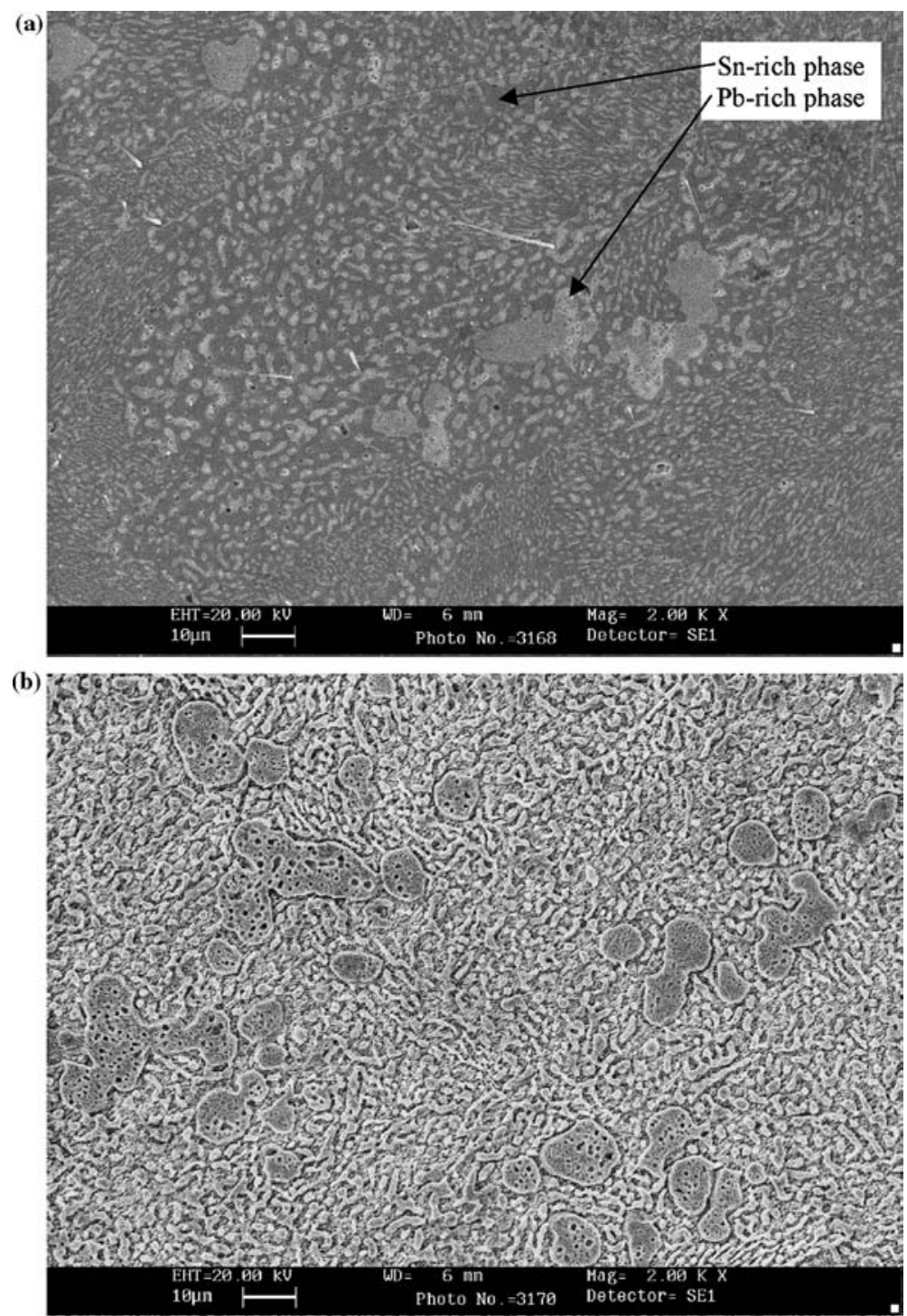

Figure 4. Initial microstructure of $\mathrm{Sn}-\mathrm{Pb}$ solder. (a) unetched, lighter $\mathrm{Pb}$-rich phase, darker $\mathrm{Sn}$-rich phase. (b) etched, Sn-rich phase removed.

acquisition software, image magnification and the storage of high resolution image files could be achieved. The location of a particular area on specimen was locked and traced by the software. Furthermore, the visual contrast and numerous gray levels of the acquired images could also be adjusted to enhance their quality for analysis. To capture a high magnification image, the cross-head displacement was halted for a sharp image. At that moment, stress relaxation occurred and some preliminary tests were done to reveal stress relaxation effects. After capturing the image, the applied load was reverted to the level before halting. Two typical force-displacement plots are shown in Figure 5. In Figure 5a, loading was suspended several times for taking microscopic graphs. In Figure 5b, the loading process was continuous. 

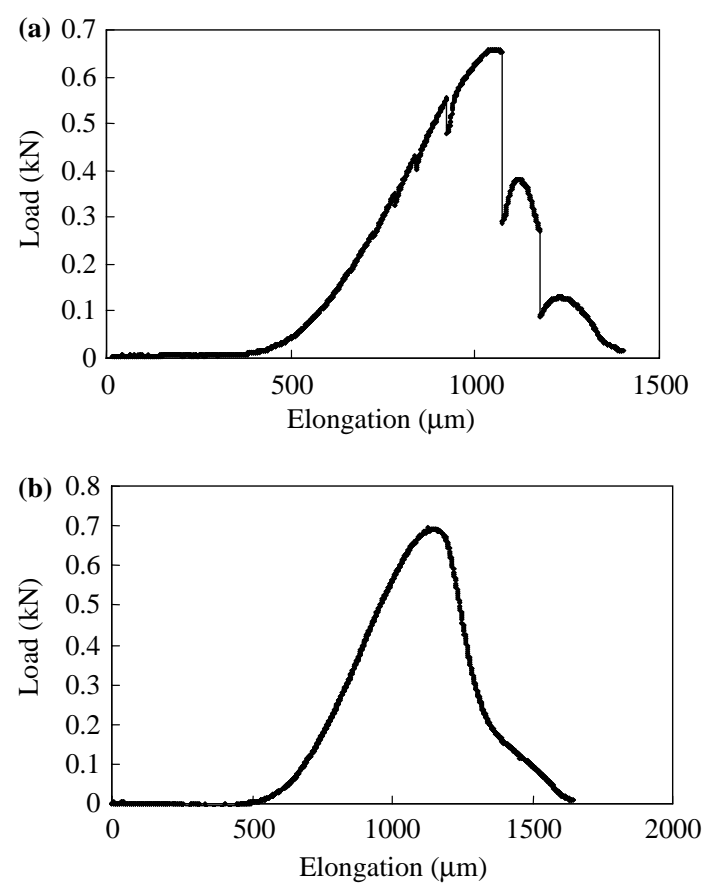

Figure 5. Force-displacement curves. (a) with displacement holds. (b) continuous loading.

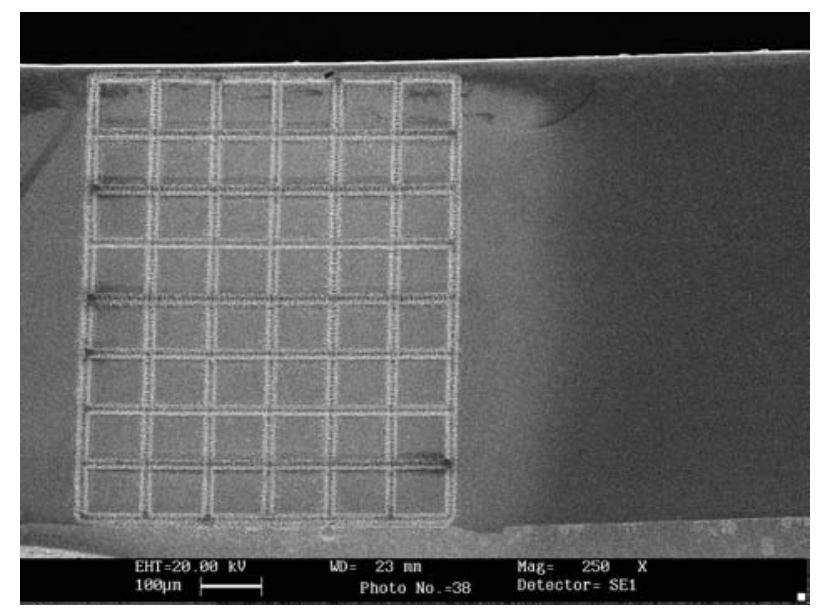

Figure 6. The laser-marked square grid.

The laser-marked square grid is shown in Figure 6. The deformation of the grid was captured by SEM graphs. The position and region under investigation and measurement are shown in Figure 7. The stress-strain curves between $\mathrm{H}$ and $\mathrm{K}$ is shown in Figure 8.

While the back-face strain was measured using the grid in this study, it would be helpful to be able to predict the displacement value at which the critical strain will occur. A damage-coupled finite element model by Wei and Chow (2001) was used for a full-field analysis of the lap shear specimen. The model was coded in the user subroutine (UMAT) of the finite element package ABAQUS and is used 

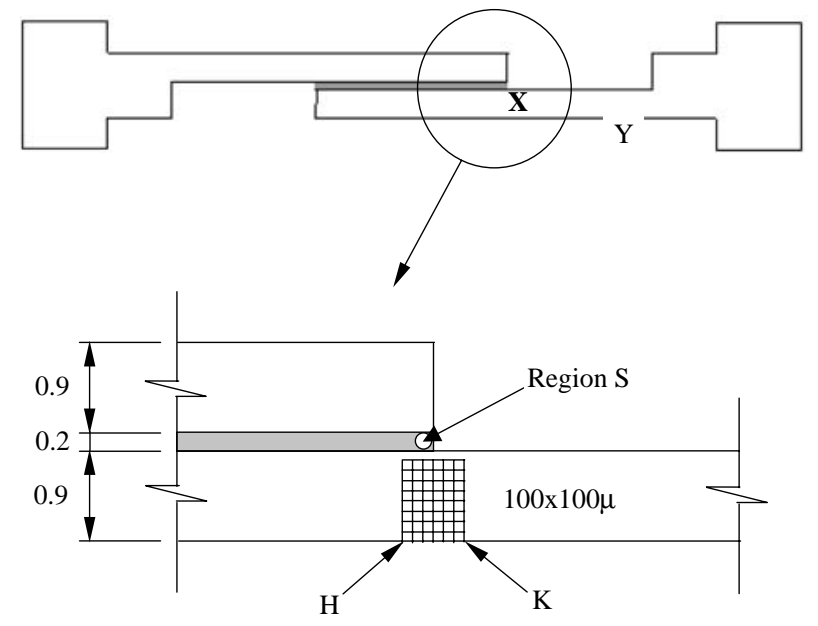

Figure 7. Position and region for observation and measurement.

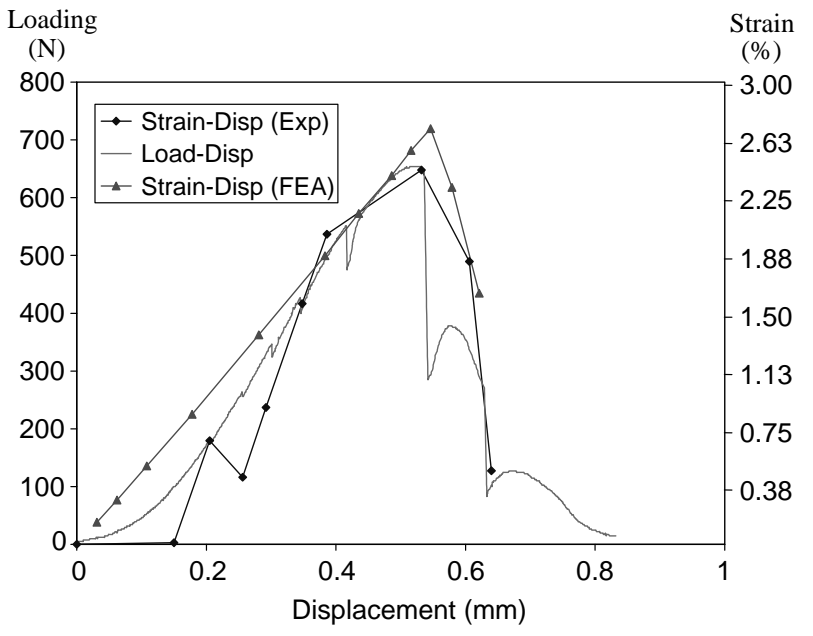

Figure 8. The load/strain-displacement curves between $\mathrm{H}$ and $\mathrm{K}$.

to predict the non-linear load-displacement relationship by incorporating the stressstrain relationship for the eutectic solder and monitoring of damage evolution in the joint. The procedure is similar in principle to the conventional FEM analysis, except that the tangent modulus measured from tensile test is coupled with the damage variables. The 8-node linear brick element (Type C3D8R) was chosen in ABAQUS and there are totally 1080 elements being meshed for both copper and solder materials in quadrilateral shape. The damage-coupled elastic constitution is written as

$$
\varepsilon^{e}=\mathbf{C}^{-1}: \sigma \quad \sigma=\mathbf{C}: \varepsilon^{e}
$$

where the total strain rate is given by 


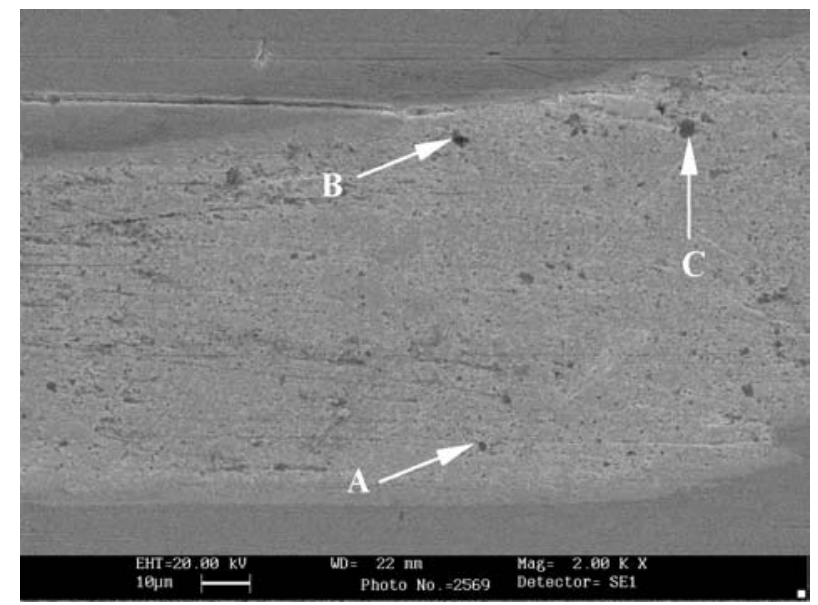

Figure 9. The three selected reference points in region $\mathrm{S}$ of the solder material.

$\dot{\varepsilon}=\dot{\boldsymbol{\varepsilon}}^{e}+\dot{\boldsymbol{\varepsilon}}^{\text {in }}$

with inelastic strain rate $\dot{\boldsymbol{\varepsilon}}^{\text {in }}=\dot{p}^{\text {in }} \frac{3}{2} \frac{\mathbf{S}-\boldsymbol{X}}{J_{2}}$

in which $J_{2}=\left\{\frac{3}{2}(\mathbf{S}-\boldsymbol{X})^{T}:(\mathbf{S}-\boldsymbol{X})\right\}^{\frac{1}{2}}$

and

$$
\dot{p}^{\text {in }}=\left\{\frac{2}{3} \dot{\varepsilon}^{\text {in }}: \dot{\varepsilon}^{\text {in }}\right\}^{\frac{1}{2}}
$$

$\boldsymbol{X}$ is the backstress and $C^{-1}$ is the effective elastic tensor for damaged materials, being functions of instantaneous values of the Young's modulus and Poisson's ratio. Two internal state variables, known as damage parameters, are used to characterize material degradation due to the change of material microstructure under load. Then, a damage effect tensor is used to define the effective stress for a damaged material, while damage evolution equations employed are based on irreversible thermodynamics. For details please refer to Wei and Chow (2001). As the load increases, elements are removed of its load carrying capabilities when a critical damage value has been attained in that element. The finite element analysis results are also shown in Figure 8. It can be seen that a reasonable estimation of the critical crosshead displacement can be obtained. Some observations on stress patterns obtained from the finite element analysis is also described in the discussions section.

In order to estimate the shear strain in Region $\mathrm{S}$ corresponding to a specific state of damage, three characteristic points, $\mathrm{A}, \mathrm{B}$ and $\mathrm{C}$, were selected as the reference points to measure local strain, as shown in Figure 9. The shear strain in Region $\mathrm{S}$ can be calculated according to the relative displacements among A, B and C (Tang et al., 2002).

The shear force-shear strain curve of the solder is shown in Figure 10. The microstructure at the final stage is shown in Figure 11. The typical load-displacement 


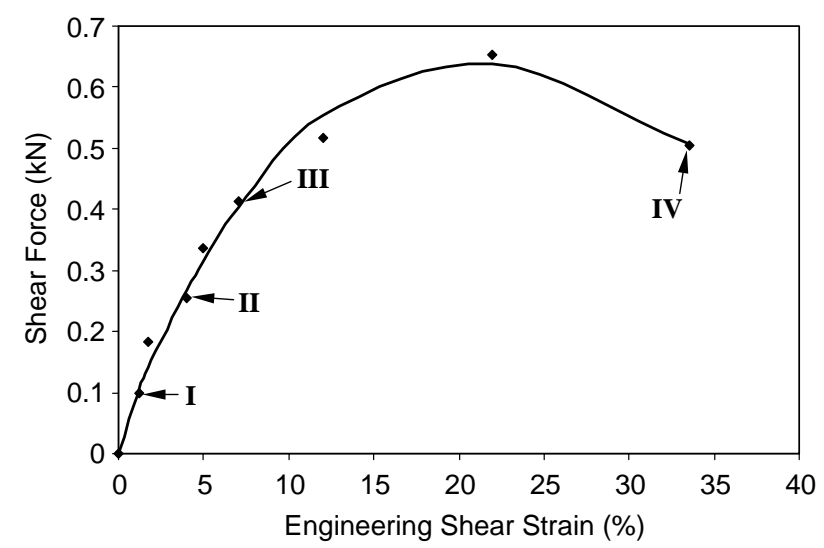

Figure 10. Shear force-Shear strain curve of the solder in region S.

curve of the lap shear joint specimen under monotonic tensile test is shown in Figure 12. As the microstructure of the specimen was observed under the SEM throughout the test, the corresponding micrographs were provided on the same figure to indicate the initiation and propagation of the shear crack. A micrograph of the etched fracture surface is shown in Figure 13.

\subsection{LEAD-FREE SOLDERS $(97 \mathrm{Sn}-3 \mathrm{Cu}$ and $95.5 \mathrm{Sn}-3.5 \mathrm{Ag}-1 \mathrm{Cu})$}

Laser marking and back-strain measurements were not repeated on the lead-free solder joints. Other than that, specimen preparation procedure was the same as that for the above leaded solder. The initial microstructures are shown in Figure 14. The test curves are given in Figure 15. Microscopic examination of fracture areas are shown in Figure 16.

\section{Discussions}

\subsection{LEADED SOLDER $(64 \mathrm{Sn}-36 \mathrm{~Pb})$}

In Figure 4, there are two distinct phases in the $64 \mathrm{Sn}-36 \mathrm{~Pb}$ solder. The lighter region in Figure $4 \mathrm{a}$ belongs to $\mathrm{Pb}$-rich phase while the darker region is the $\mathrm{Sn}$-rich phase. After the solder surface was etched, Sn-rich phase on the surface was removed as shown in Figure 4b. In Figure 5a it can be seen that stress relaxation occurred while the cross-head movement was suspended to capture the corresponding microscopic graphs. On comparing with the results in Figure 5b, the stress relaxation induced by the suspension of loading does not have obvious effects on shear bearing ability and deformation of the solder. So the stress relaxation due to the suspension of loading in the tests does not cause an obvious effect on the load-deformation relationship of the specimen.

From microscopic observations, both from unetched and etched specimens (Figure 4), the original eutectic alloy consists of $\mathrm{Pb}$-rich (89\%) phase surrounded by a tin-rich $(97 \%)$ phase. After loading, microstructural changes occurred throughout the whole loading process to failure. The shear force-shear strain curve of the solder 
(a)

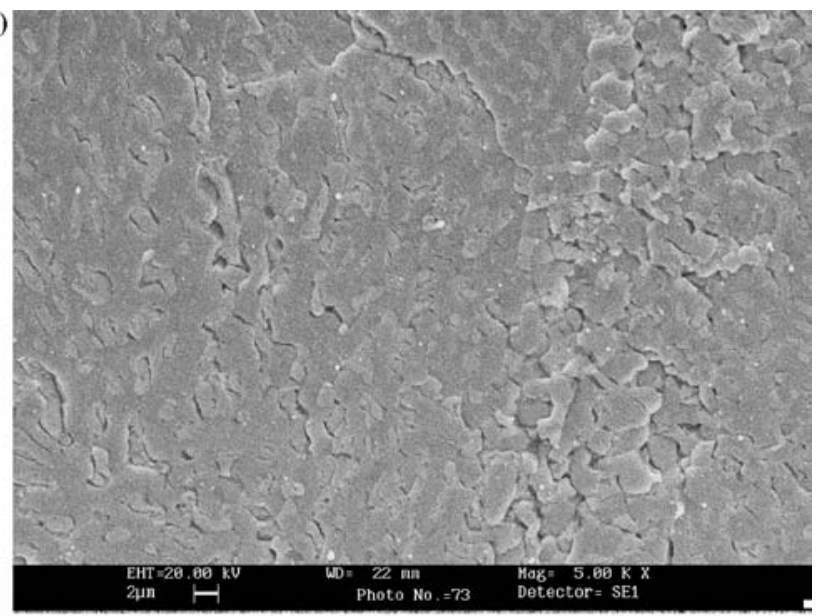

(b)

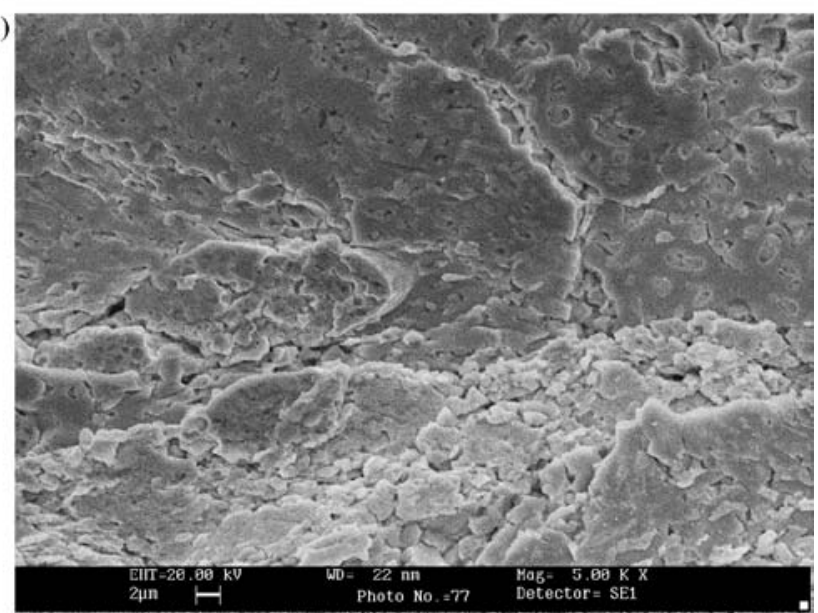

(c)

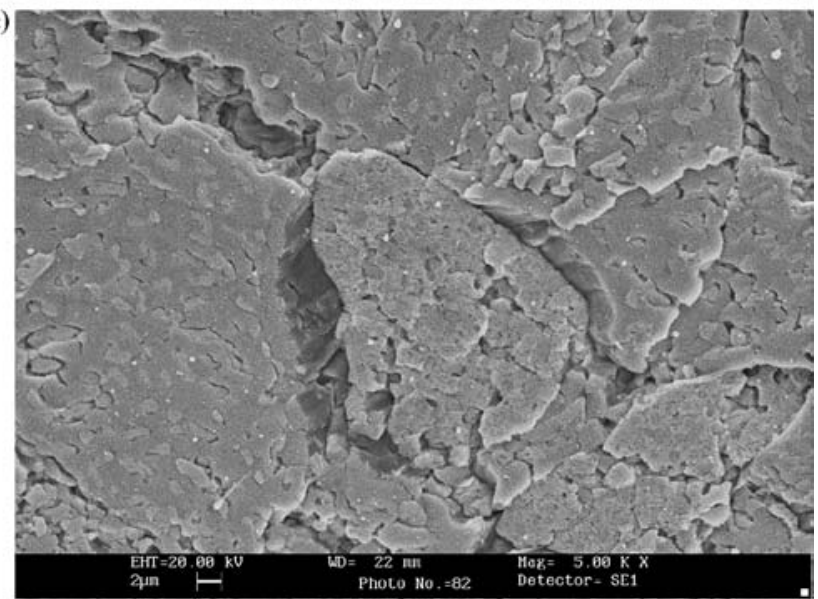

Figure 11. Microstructures at different stages. (a) at stage III. (b) at stage IV. (c) just before failure.

is shown in Figure 10. No apparent change occurred in the microstructure from the point I to point II in Figure 10. At point III, some fine cracks and voids were around $\mathrm{Pb}$-rich grains as shown in Figure 11a. At this stage, the solder began to lose its 


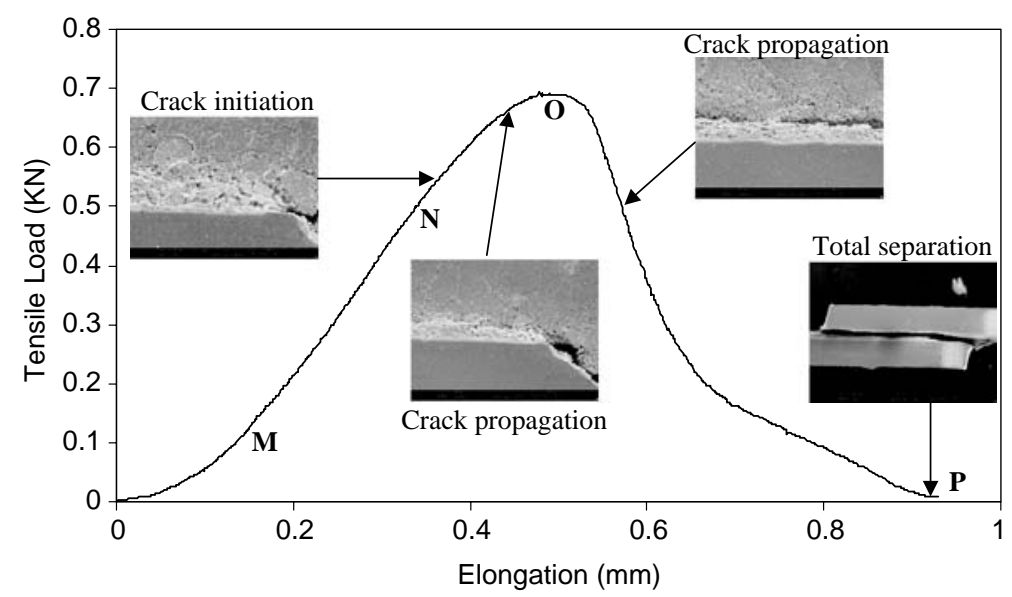

Figure 12. Typical Load-Displacement curve for $\mathrm{Sn}-\mathrm{Pb}$ specimen.

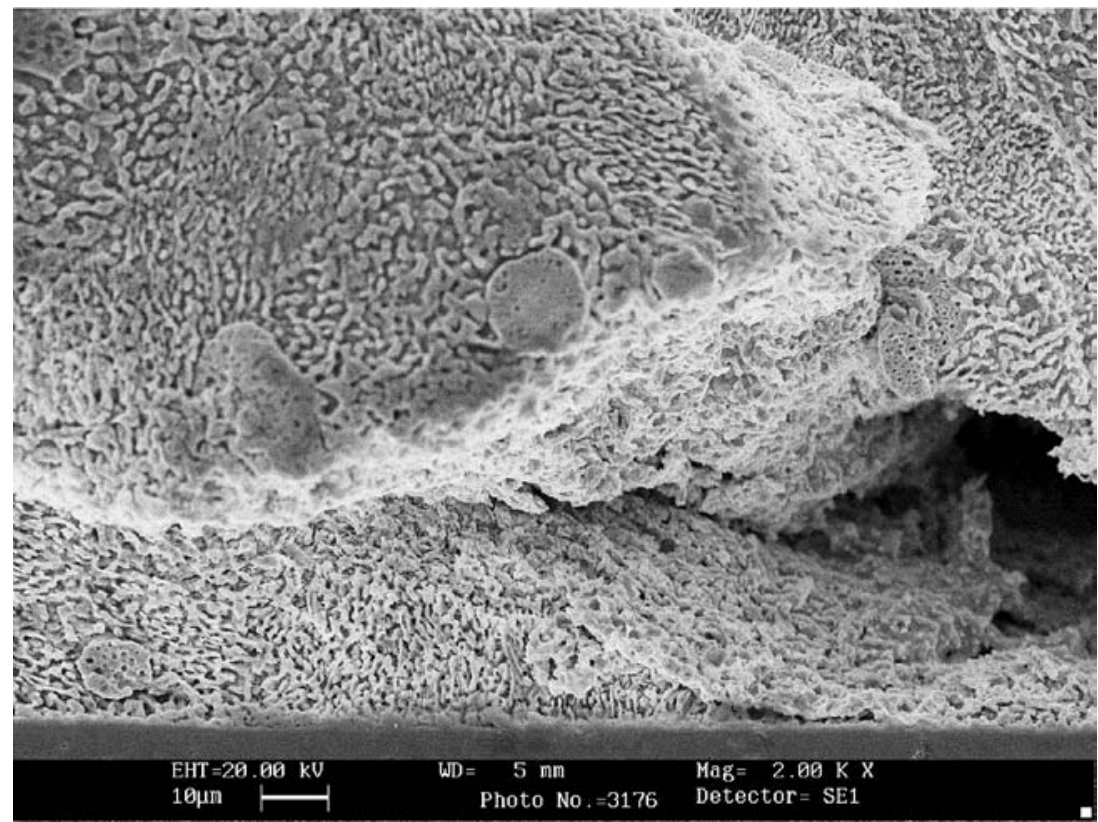

Figure 13. Soft band in etched fracture surface of $\mathrm{Sn}-\mathrm{Pb}$ specimen.

shear force bearing ability. At the final stage indicated as the point IV in Figure 10 , the micro-cracks and micro-voids linked up, and many grains had debonded as shown in Figure 11b. The microstructure just before failure is shown in Figure 11c, in which most grains had debonded.

From Figure 12, a direct relation between the 'interphase (Pb-rich and Sn-rich phases) debonding' and the stress relaxation can be observed. At the initial stage of the test, the specimen deforms elastically without the interphase debonding at point $\mathrm{M}$. Then, as loading increases to the stage at point $\mathrm{N}$, the interphase debonding had occurred within the solder, causing a crack initiation at the region of shear stress 

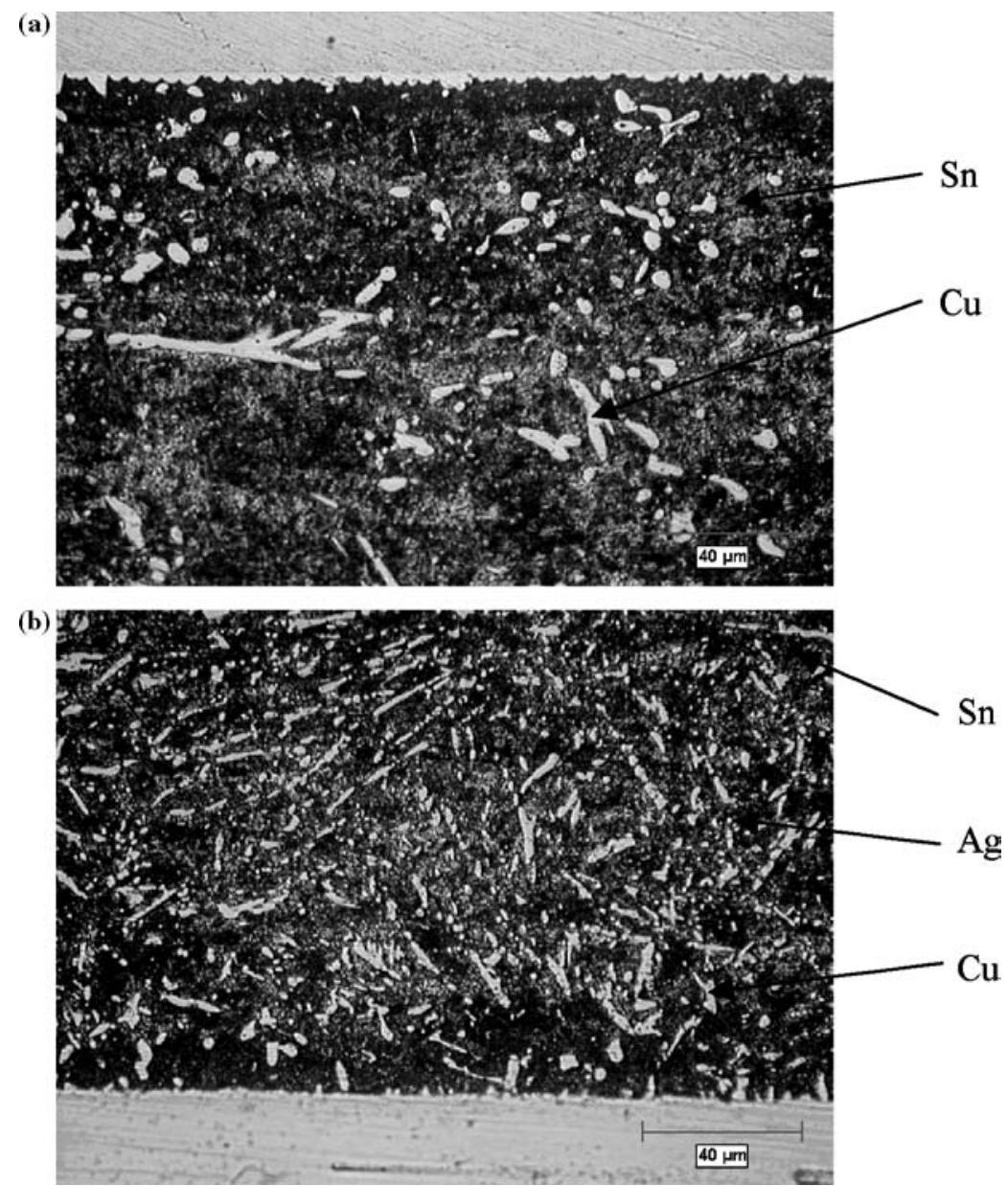

Figure 14. Initial microstructure of lead-free solders. (a) $97 \mathrm{Sn}-3 \mathrm{Cu}$. (b) $95.5 \mathrm{Sn}-3.5 \mathrm{Ag}-1 \mathrm{Cu}$.

concentration and propagation towards the centre of the solder. A shear band consisting of the debonded grains was formed in front of the crack.

The load continues to rise up to the maximum load at point $\mathrm{O}$. At this point, the coalescence of micro-cracks and micro-voids occurs within the solder material near the free end and hence a macrocrack was formed. Beyond the point $\mathrm{O}$, the load gradually decreases with the increase in the extension. The extension is exculsively due to the propagation of the macrocrack. The load eventually vanishes at point $\mathrm{P}$ when the macrocrack extends fully across the specimen and a ductile shear fracture was observed. Microscopic examination of the etched fracture specimen shown in Figure 13 reveals that the shear band is similar to those found for plastically deformed $\mathrm{Pb}$-rich phase along colony boundaries in the specimen fractured due to fatigue (Logsdon et al., 1990).

From all the experimental data of this kind of lap shear specimens, fracture occurs within the solder material close to the interface of the copper substrate instead of occurring right at the interface. This is called the 'boundary layer fracture' (Pratt and Quesnel, 1992; Wasynczuk and Lucey, 1992). 
630 K.J. Lau et al.

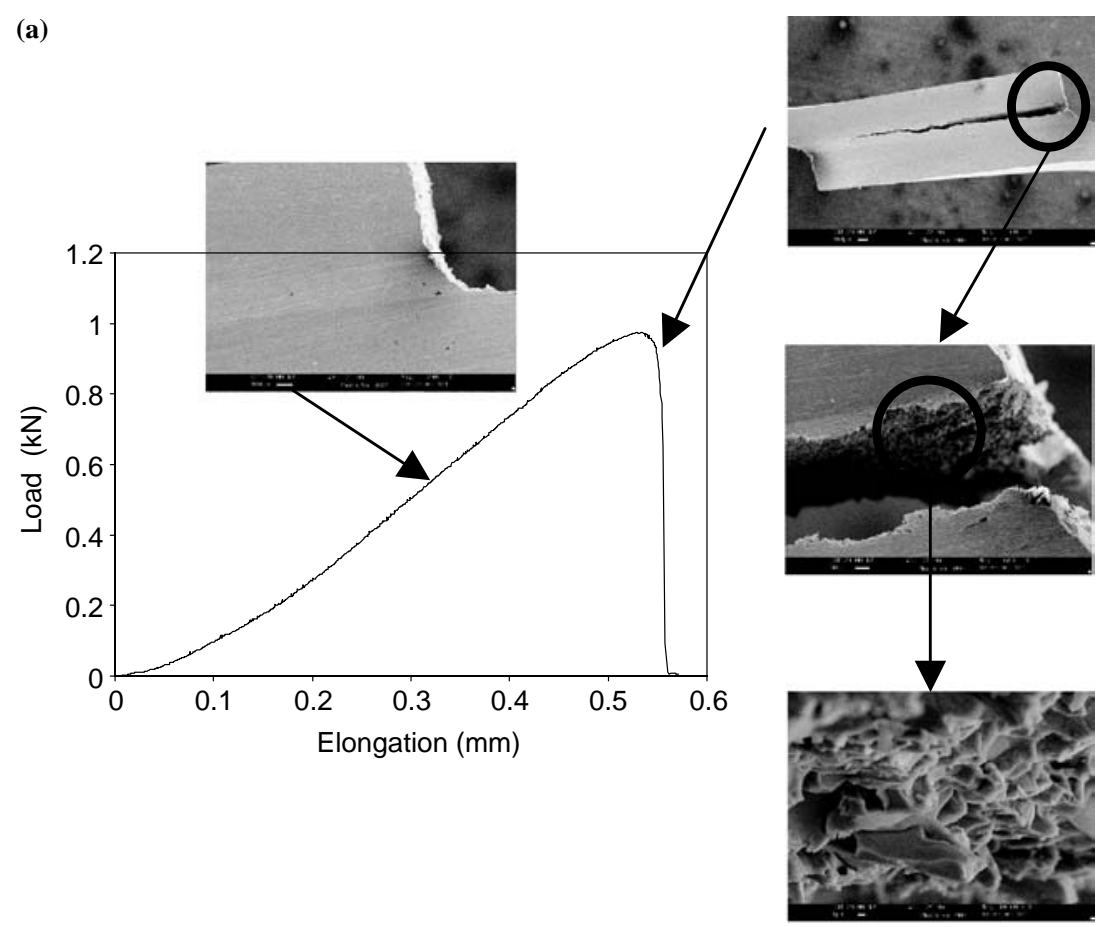

(b)

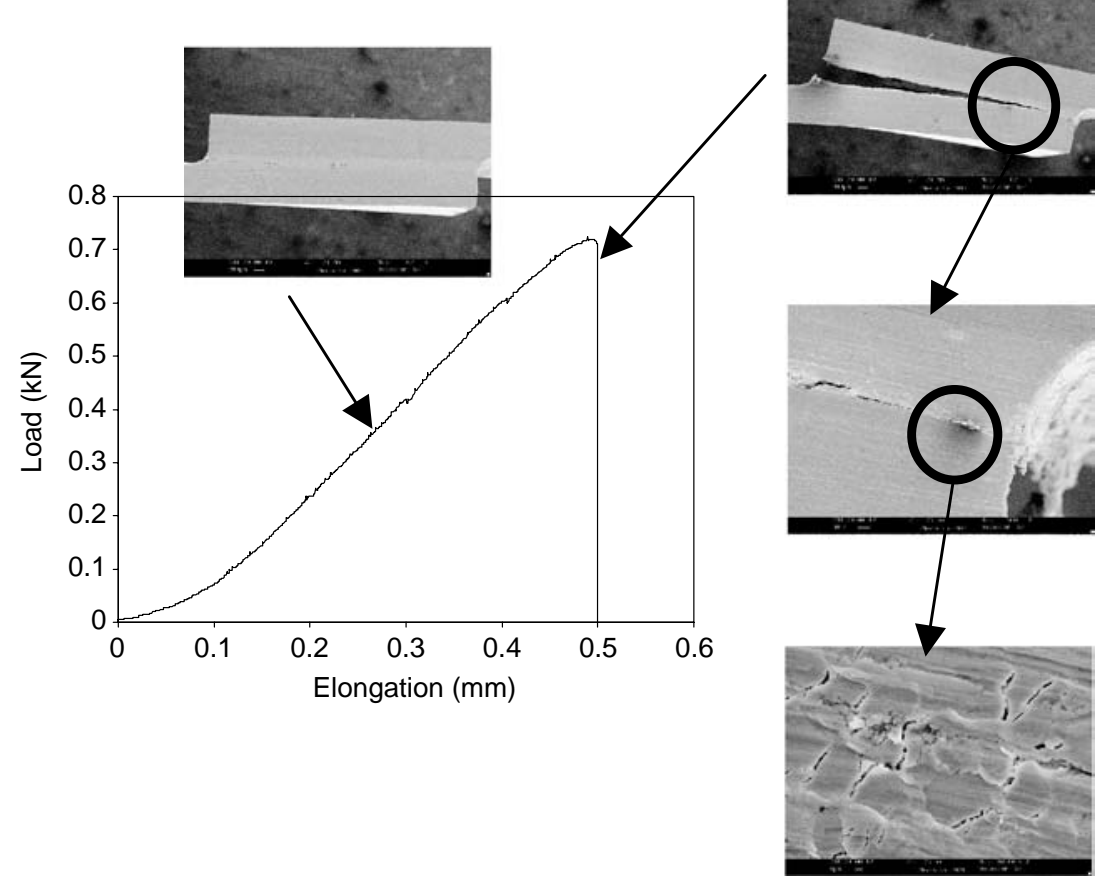

Figure 15. Load-displacement curves for lead-free solders. (a) $97 \% \mathrm{Sn}, 3 \% \mathrm{Cu}$. (b) $95.5 \% \mathrm{Sn}, 1 \% \mathrm{Cu}$, $3.5 \%$ Ag. 
(a)

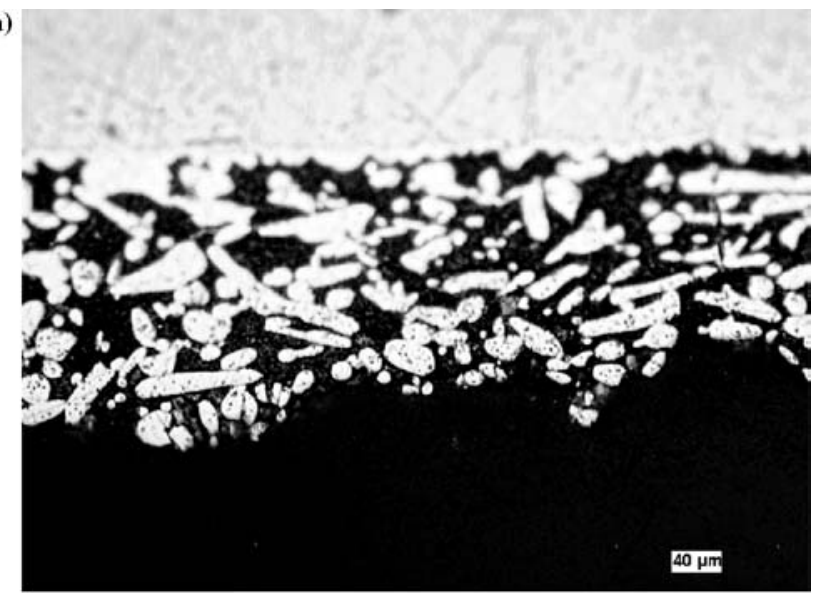

(b)

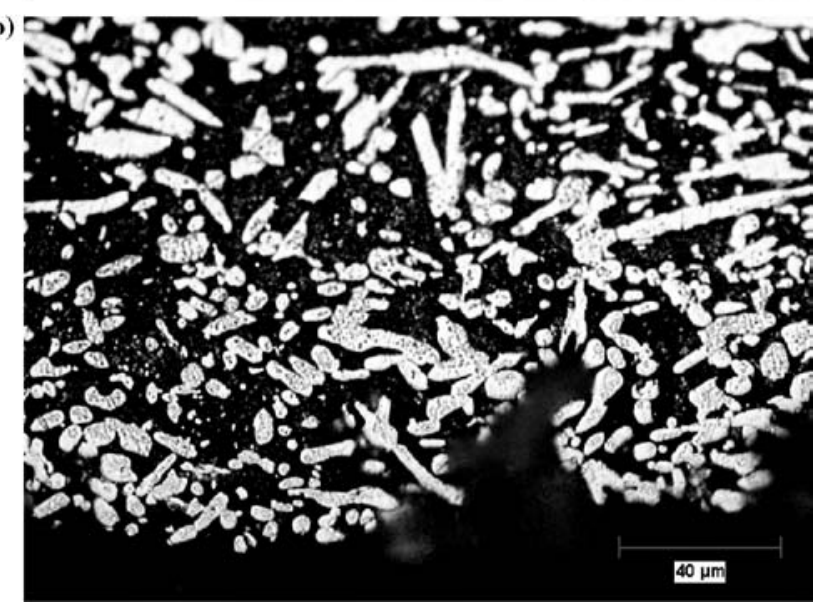

Figure 16. Fracture surfaces of lead-free solders. (a) $97 \mathrm{Sn}-3 \mathrm{Cu}$. (b) $95 \mathrm{Sn}-3.5 \mathrm{Ag}-1 \mathrm{Cu}$.

In Figure 8, satisfactory agreement is obtained between the measured strain values and results of finite element analysis. The discrepancy is found to be less than $10 \%$. From the finite element stress analysis plots, the maximum stress of the entire model initially occurs at the free end of the solder material. As the load increases, the maximum stress location is then shifted across the solder material. For the copper substrate, the maximum stress was first located at $\mathrm{X}$ in Figure 7. Once the macro crack of solder material has been initiated, the maximum stress location is shifted from location X to location Y. Such a shift leads to the sudden drop of back-face strain shown in Figure 8.

\subsection{LEAD-FREE SOLDERS ( $97 \mathrm{Sn}-3 \mathrm{Cu}$ and $95.5 \mathrm{Sn}-3.5 \mathrm{Ag}-1 \mathrm{Cu})$}

The initial microstructure of the $97 \mathrm{Sn}-3 \mathrm{Cu}$ binary solder shown in Figure $14 \mathrm{a}$ consists of the intermetallic $\mathrm{Cu}_{6} \mathrm{Sn}_{5}$ (the brighter phase) dispersed in the $\beta$-Sn matrix. The initial microstructure of $95.5 \mathrm{Sn}-3.5 \mathrm{Ag}-1 \mathrm{Cu}$ ternary solder shown in Figure $14 \mathrm{~b}$ consists of primary $\beta$-Sn grains surrounded by the intermetallic compound $\mathrm{Ag}_{3} \mathrm{Sn}$ and $\mathrm{Cu}_{6} \mathrm{Sn}_{5}$, and $\mathrm{Sn}$-rich phases. Both solders were sheared to maximum load and 


\section{K.J. Lau et al.}

finally joint failure occurred as shown in Figure 15 . The $\mathrm{Sn}-3 \mathrm{Cu}$ has a maximum load of about $0.95 \mathrm{kN}$ and a value of elongation to failure higher than the $\mathrm{Sn}-3.5 \mathrm{Ag}-$ $1 \mathrm{Cu}$. This result is in agreement with that reported by $\mathrm{Wu}$ et al. (2004). In the case of the binary solder, the crack nucleated at the region near the interface between the solder matrix and the $\mathrm{Cu}_{6} \mathrm{Sn}_{5}$ intermetallic layer. From Figure 15a(i,ii), the crack had propagated roughly at $45^{\circ}$ to the loading direction in the beginning of the shear deformation. Later on, the main fracture path had extended roughly parallel to the interface of the solder joint. From Figure 15a(iii), evidence of large plastic deformation is seen. Like the binary solder, the crack in the ternary solder also nucleated at the region closer to but not right at the interface between the solder matrix and the intermetallic compounds as shown in Figure 15b(i). The absence of the interfacial separation between the solder matrix and the intermetallic compounds could be found in the study of the ternary $\mathrm{Sn}-3.6 \mathrm{Ag}-1.0 \mathrm{Cu}$ solder performed by Cook et al. (2001). Moreover, the crack propagation behavior of the ternary solder as shown in Figure $15 \mathrm{~b}(\mathrm{i})$ is similar to that of the binary solder. From Figure 15b (ii,iii) captured at the moment beyond the maximum load, a number of microcracks had evolved at the grain boundary of the ternary solder. By comparing the lead-free solder with the $\mathrm{Sn}-\mathrm{Pb}$ solder, the elongation to failure of the $\mathrm{Sn}-\mathrm{Pb}$ solder shown in Figure 12 is much higher than that for the lead-free solders in this study. Thus, the microvoids and microcracks which occurred in the $\mathrm{Sn}-\mathrm{Pb}$ solder during its large deformation are more significant than those in the lead-free solder.

Post-fracture microscopic examinations of the etched fracture surfaces of the leadfree solders shown in Figure 16 reveal that the propagation of the microscopic cracks along the grains resulted in a transgranular fracturing occurring in these solders. This is consistent with the observations from the $\mathrm{Sn}-\mathrm{Pb}$ solder joint. The coalescence of numerous microcracks into large macrocracks is the probable cause of the rapid rate of crack growth at specimen fracture. Work is underway to formulate constitutive and damage models to carry out further investigations on these lead-free solders as those done for the $\mathrm{Pb}-\mathrm{Sn}$ solder.

\section{Conclusions}

A non-contacting strain measurement method has been used to simultaneously measure the strain and capture the microstructure changes at a local point in the solder joint. The method can be further developed to study their quantitative relationship. The following summarizes specific findings in this study:

(i) Where in situ measurements and micrographs are recorded they can reveal the continual development of damage and fracture mechanisms consistent with observations generated by low-cycle fatigue loading. This means that the shear test can be used as alternative test to fatigue loading tests.

(ii) Sequence of events leading to failure of the solder joints consists of formation and linking up of micro-voids and propagation of the macro-crack thus formed ending in ductile shear fracture.

(iii) By comparison, the two lead-free solders specimens showed much smaller elongation to failure than the leaded solder.

(iv) All specimens exhibited the boundary layer fracture phenomenon. 
(v) A damage-coupled finite element procedure has been implemented in ABAQUS through its UMAT subroutine for failure analysis. A reasonable prediction on the crosshead displacement at which the critical back-face strain occurs is obtained.

(vi) The back-face strain indicator for the formation of a macro crack is due to the shifting of high stress concentration area from the joint-edge region to outside the joint region.

\section{Acknowledgments}

The work described in this paper has been supported by the Research Grants Council of Hong Kong, China (Project No. PolyU 5150/99E) and the Hong Kong Polytechnic University research fund G-T407.

\section{References}

Clough, R.B., Shapiro, A.J., Bayba, A.J. and Lucey, G.K. Jr. (1995). Boundary layer fracture in composite solder joints. Journal of Electronic Packaging 117, 270-274.

Cook, B.A., Anderson, I.E., Harringa, J.L., Terpstra, R.L., Folley, J.C., Unal, O. and Laabs, F.C. (2001). Shear deformation in $\mathrm{Sn}-3.5 \mathrm{Ag}$ and $\mathrm{Sn}-3.6 \mathrm{Ag}-1.0 \mathrm{Cu}$ solder joints subjeted to asymmetric four-point bend tests. Journal of Electronic Materials 30, 1214-1221.

Guo, Z. and Conrad, H. (1996). Effect of microstructure size on deformation kinetics and thermomechanical fatigue of $63 \mathrm{Sn} 37 \mathrm{~Pb}$ solder joints. Journal of Electronic Packaging 118, 49-54.

Kanchanomai, C., Miyashita, Y. and Mutoh, Y. (2002a). Strain-rate effects on low cycle fatigue mechanism of eutectic $\mathrm{Sn}-\mathrm{Pb}$ Solder. International Journal of Fatigue 24, 987-993.

Kanchanomai, C., Yamamoto, S., Miyashita, Y., Mutoh, Y. and McEvily, A.J. (2002b). Low cycle fatigue test for solders using non-contact digital image measurement system. International Journal of Fatigue 24, 57-67.

Kariya, Y. and Otsuka, M. (1998a). Effect of bismuth on the isothermal fatigue properties of $\mathrm{Sn}$ 3.5mass\%Ag solder alloy. Journal of Electronic Materials 27, 866-870.

Kariya, Y. and Otsuka, M. (1998b). Mechanical fatigue characteristics of $\mathrm{Sn}-3.5 \mathrm{Ag}-\mathrm{X}$ (X= Bi, Cu, Zn and In) solder alloys. Journal of Electronic Materials 27, 1229-1235.

Logsdon, W.A., Liaw, P.K. and Burke, M.A. (1990). Fracture behavior of $63 \mathrm{Sn}-37 \mathrm{~Pb}$ solder. Engineering Fracture Mechanics 36, 183-218.

Pang, H.L.J., Tan, K.H., Shi, X.Q. and Wang, Z.P. (2001). Microstructure and intermetallic growth effects on shear and fatigue strength of solder joints subjected to thermal cycling aging. Materials Science and Engineering A307, 42-50.

Pratt, R.E. and Quesnel, D.J. (1992). The application of fracture mechanics to solder joint failures. The Metal Science of Joining, The Metallurgical society.

Shang, J.K. and Yao, D. (1996). Effect of interface roughness on fatigue crack growth in $\mathrm{Sn}-\mathrm{Pb}$ solder joints. Journal of Electronic Packaging 118, 170-173.

Solomon, H.D. (1986). Fatigue of 60/40 solder. IEEE Transactions CHMT 9, 423-432.

Tang, C.Y., Lee, T.C., Chow, C.L. and Rao, B. (2002). An experimental study of shear damage using in-situ single shear test. International Journal of Damage Mechanics 11, 335-353.

Wasynczuk, J.A. and Lucey G.K. Jr. (1992). Shear creep of $\mathrm{Cu}_{6} \mathrm{Sn}_{5} / \mathrm{Sn}-\mathrm{Pb}$ eutectic composites, Proceedings of the Technical Program, NEPCON West'92, National Electronic Packaging and Production Conf. (NEPCON). Vol. III NEPCON, Anaheim, CA, pp. 1245-1255.

Wei, Y. and Chow, C.L. (2001). A damage-coupled TMF constitutive model for solder alloy. International Journal of Damage Mechanics 10, 133-152.

Wu C.M.L., Yu D.Q., Law C.M.T. and Wang L. (2004). Properties of lead-free solder alloys with rare earth element additions. Materials Science and Engineering $R$ 44, 1-44.

Yao, D., Shang, Z. and Shang, J.K. (1996). An experimental technique for studying mixed-mode fatigue crack growth in solder joints. Journal of Electronic Packaging 118, 45-48. 
634 K.J. Lau et al.

Zang, Z., Yao, D. and Shang, J.K. (1996). Fatigue crack initiation in solder joints. Journal of Electronic Packaging 118, 41-44.

Zhao, J., Miyashita, Y. and Mutoh, Y. (2001). Fatigue crack growth behavior of 96.5Sn-3.5Ag lead-free solder. International Journal of Fatigue 23, 723-731. 